\title{
Indentation creep studies of iron aluminide intermetallic alloy
}

\author{
Garima Sharma $^{\text {a,* }}$, R.V. Ramanujan ${ }^{\text {b }}$, T.R.G. Kutty ${ }^{\mathrm{c}}$, N. Prabhu ${ }^{\mathrm{d}}$ \\ ${ }^{a}$ Materials Science Division, BARC, Mumbai, India \\ ${ }^{\mathrm{b}}$ School of Materials Engineering, Nanyang Technological University, Singapore \\ ${ }^{\mathrm{c}}$ Radiometallurgy Division, BARC, Mumbai, India \\ ${ }^{4}$ Indian Institute of Technology, Mumbai, India
}

\begin{abstract}
Indentation creep behaviour of iron aluminide intermetallic ( $\mathrm{Fe}-28 \mathrm{Al}-3 \mathrm{Cr}$ ) was studied in the temperature range of $843-963 \mathrm{~K}$. The hardness and the plasticity parameter were also calculated from room temperature to $1273 \mathrm{~K}$. The variation of hardness with time showed that the stress exponent $(n)$ was weakly dependent on temperature. Thermal activation parameter-activation area and energy were also calculated to identify the creep mechanism. The activation energy for high temperature creep was found to be in good agreement with that for selfdiffusion of pure iron and in excellent agreement with previous studies. These values of $\mathrm{n}$, activation area and activation energy were found to be consistent with dislocation climb as the rate controlling creep mechanism. Conventional creep curves were also derived from hardness values.
\end{abstract}

Keywords: A. Iron aluminides (based on $\mathrm{Fe}_{3} \mathrm{Al}$ ); B. Creep (properties and mechanisms); B. Mechanical properties at high temperatures

\section{Introduction}

The indentation creep test provides a simple and nondestructive method of investigating the mechanical properties of solids, it also gives information about the time dependent flow of materials [1-4]. In this test, the indenter is maintained at a constant load over a period of time under well-controlled conditions. As the stresses cause the material beneath the indenter to creep, the indenter penetrates and changes in the indentation size are monitored. Thus, indentation creep is the time dependent motion of a hard indenter into a solid under constant load [5,6]. An important advantage of the indentation creep technique is that all the creep information can be collected from the same sample, which not only greatly reduces the effort for sample preparation but also reduces the sample to sample variation in property [7]. This technique can be used for studying the creep properties of high temperature materials such as intermetallics and ceramics, including diamond, which are very difficult to evaluate using conventional methods. Thus, indentation method can be regarded as a quick and non-destructive procedure to extract information on the mechanical behaviour of materials [6-8].

Iron aluminides based on $\mathrm{B} 2$ or $\mathrm{DO}_{3}$ ordered $\mathrm{Fe}_{3} \mathrm{Al}$ based alloys are now receiving extensive attention as materials with good potential for industrial applications as replacement for high temperature oxidation resisting or corrosion resisting stainless steel [9-11]. The lack of ductility at room temperature and a decrease in strength above $873 \mathrm{~K}$ had retarded their development as a structural material. However, improvement in the room temperature ductility of $\mathrm{Fe}_{3} \mathrm{Al}$ has been achieved recently by the addition of alloying elements such as $\mathrm{Cr}[11,12]$. Efforts are continuing to develop iron aluminides with improved high temperature tensile and creep-properties. Much effort has been paid to structure control in order to optimize the mechanical properties of $\mathrm{Fe}_{3} \mathrm{Al}$ based alloys. In general, the alloys show various types of creep behaviour, which depends on condition such as stress, temperature, grain size and alloy composition [9-24]. The aim of the present paper is to study the creep properties of this alloy by the indentation creep method. 


\subsection{Sargent and Ashby's model of indentation creep}

In this model, Sargent and Ashby [25] have suggested that the stress and strain fields in a material below the pyramidal indenter are self similar in time and creep deformation is found to follow the power law of the type

$\dot{\epsilon}=A^{\prime} \sigma^{n} \exp \left(\frac{-Q}{R T}\right)$

where $\dot{\epsilon}$ is the steady state strain rate, $A^{\prime}$ is a constant, $\sigma$ is the applied stress, $n$ is the stress exponent, $Q$ is the activation energy and $R$ is the universal gas constant

The displacement rate of an indentor in the underlying material has been derived as

$$
\frac{\mathrm{d} u}{\mathrm{~d} t}=\left(\frac{\dot{\epsilon}_{0}(\sqrt{A})}{C_{2}}\right)\left(\frac{P}{A} \frac{C_{1}}{\sigma_{0}}\right)^{n}
$$

where $A$ is the projected area of indentation, $C_{2}$ is a constant and $\dot{\epsilon}_{0}$ is the strain rate at a reference stress $\sigma_{0}$. For a pyramidal indentor the penetration is proportional to $\sqrt{A}$, i.e.,

$u=C_{3}(\sqrt{A})$

Differentiating Eq. (3) with respect to time and substituting into Eq. (2),

$$
\frac{\mathrm{d} A}{\mathrm{~d} t}=C_{4} \dot{\epsilon}_{0} A\left(\frac{P}{A \sigma_{0}}\right)^{n}
$$

where $C_{3}$ and $C_{4}$ are constants. Substituting hardness $(H)=P / A$ where $P$ is the normal load and $A$ is area of penetration, Sargent and Ashby [25] have derived the following relationship between indentation hardness and dwell time:

$H(t)=\frac{\sigma_{0}}{\left(n C_{4} \dot{\epsilon}_{0} t\right)^{1 / n}}$

where $H(t)$ is the time dependent hardness. From Eq. (4), when $P$ is held constant, we get

$\left(\frac{1}{H}\right)\left(\frac{\mathrm{d} H}{\mathrm{~d} t}\right)=-C_{4} \dot{\epsilon}_{0}\left(\frac{H}{\sigma_{0}}\right)^{n}$

Hence, from Eq. (5) the gradient of a plot of $\ln (H)$ against $\ln (t)$ at a constant temperature is $-1 / n$. Also a plot of $\ln (H)$ versus $\ln [(-1 / H)(\mathrm{d} H / \mathrm{d} t)]$ at a constant temperature has a slope $n$ (from Eq. (6)). The activation energy is calculated from the plot of $\ln (t)$ against $1 / T$ at constant hardness, the slope of which provides $Q / R$.

\section{Experimental procedure}

The nominal alloy composition used in this study was $\mathrm{Fe}-28 \mathrm{Al}-3 \mathrm{Cr}(\mathrm{at} \%)$. Samples were prepared by air induction melting followed by electro-slag re-melting, using high purity elements. The microstructure of the alloy consists of equiaxed grains with an average grain size of $414 \mu \mathrm{m}$. The hot hardness measurements were carried out using a Nikon hot hardness tester (Nikon, Model QM) equipped with diamond Vickers micro-hardness indenter. Before starting the hot hardness experiments, the instrument was calibrated using standard samples (Cu: SRM; National Bureau of Standards, USA). Five indentations were made on the standard using $0.2 \mathrm{~kg}$ load. The hardness obtained was found to be $\pm 0.5 \%$ of the actual value. Samples of $5 \mathrm{~mm} \times 5 \mathrm{~mm}$ were cut from the alloy and metallographically prepared. The sample was loaded into the furnace of the hot hardness tester and evacuated to $0.1 \mathrm{~Pa}$. The hardness was measured from room temperature to $1000{ }^{\circ} \mathrm{C}$ at $100{ }^{\circ} \mathrm{C}$ intervals with a dwell time of $5 \mathrm{~s}$. All measurements were taken in the central region of the sample. At each temperature, at least four indentations were taken.

The indentation creep measurements were carried out using a load of $0.2 \mathrm{~kg}$ at $843,873,903,933$ and $963 \mathrm{~K}$. This choice of temperature was based on the known softening behaviour of this class of alloys. At each temperature, the hardness was measured as a function of dwell time. The dwell times used in this study were 5, 15, 30, 100 and $300 \mathrm{~s}$. For each dwell time, at least four indentations were taken. The indentation creep was also measured in the central region of the sample and all indentations were away from the edges.

\section{Results}

The variation of hardness $(H)$ with temperature $(T)$ of $\mathrm{Fe}-28 \mathrm{Al}-3 \mathrm{Cr}$ alloy is given in Table $1 . H-T$ data of the above mentioned alloy has been analysed in detail and results are reported elsewhere [26]. The indentation creep was studied by plotting a graph between hardness and dwell time at 843, 873, 903, 933 and $963 \mathrm{~K}$ (Fig. 1). This plot showed a gradual decrease in hardness with increasing dwell time due to indentation creep. The slope of these lines is $(-1 / n)$ from which the stress exponent, $n$ was determined

Table 1

Variation of hardness with temperature

\begin{tabular}{ll}
\hline Temperature $(\mathrm{K})$ & Hardness $(\mathrm{GPa})$ \\
\hline $\mathrm{RT}$ & 3.96 \\
473 & 3.46 \\
523 & 3.62 \\
573 & 3.55 \\
623 & 3.31 \\
673 & 3.06 \\
723 & 2.96 \\
773 & 2.84 \\
873 & 1.53 \\
973 & 0.52 \\
1073 & 0.24 \\
1173 & 0.13 \\
& 0.08 \\
\hline
\end{tabular}




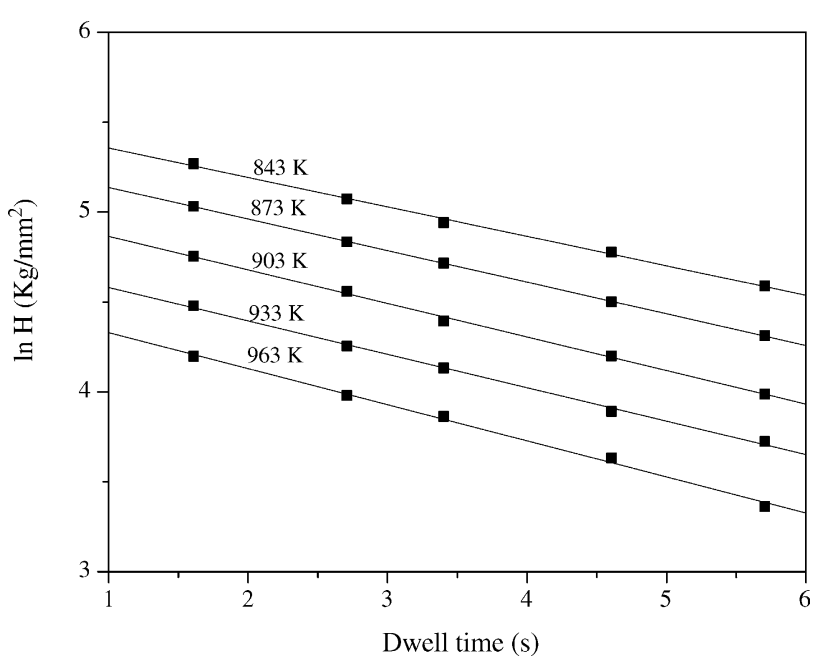

Fig. 1. $\log -\log$ plot of hardness with the dwell time. The slope of this plot is equal to $(-1 / n)$, from which the stress exponent is determined.

Table 2. The activation energy of the creep process has been calculated using a plot $\ln (t)$ vs $1 / R T$ at constant hardness (Fig. 2).

\section{Discussion}

\subsection{Hardness and plasticity parameter}

Milman et al. [27] have shown that the plasticity characteristics of a material can be evaluated from the hardness measurement They proposed a parameter called material plasticity, $\delta_{\mathrm{H}}$ defined as:

$\delta_{\mathrm{H}}=\epsilon_{\mathrm{p}} / \epsilon=1-\epsilon_{\mathrm{e}} / \epsilon$

where $\epsilon_{\mathrm{p}}$ and $\epsilon_{\mathrm{e}}$ are the plastic and elastic deformation, respectively, and $\epsilon$ is the total deformation. The plasticity parameter characterizes, in general, the material's ability to change its shape in the course of deformation and to retain a part of this change after unloading. A sharp increase of $\epsilon_{\mathrm{e}}$ during loading in a material indicates a weak stress relaxation by means of plastic deformation, i.e. low material plasticity. Plastic deformation leads to stress relaxation due to Hooke's law. For elastic deformation, Milman et al. [27] have derived a relation given below:

$\epsilon_{\mathrm{e}}=-1.08\left(1-\nu-2 \nu^{2}\right) H / E$

Table 2

Stress exponent at different temperature

\begin{tabular}{ll}
\hline Temperature $(\mathrm{K})$ & Stress exponent $(n)$ \\
\hline 843 & \\
873 & 5.52 \\
903 & 5.31 \\
933 & 5.05 \\
963 & 4.76 \\
\hline
\end{tabular}

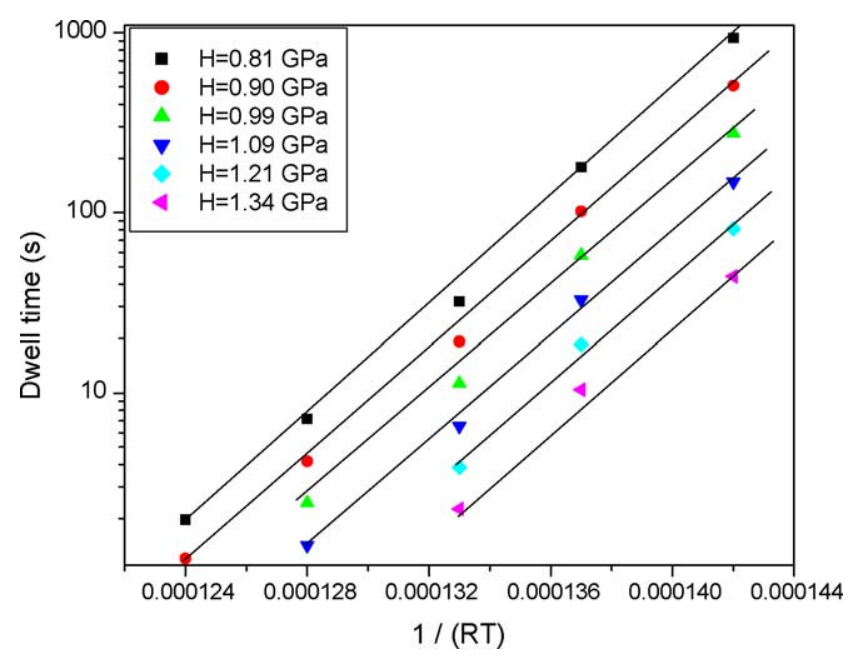

Fig. 2. The variation of dwell time with temperature, the slope of this plot yields activation energy for the high temperature creep.

The above equation can be regarded as Hooke's law of indentation loading which allows a calculation of elastic deformation of the contact area. They also derived an expression for plasticity parameter:

$\delta_{\mathrm{H}}=1-14.3\left(1-\nu-2 \nu^{2}\right) H / E$

It is seen from the above equation that the plasticity parameter is defined mainly from the value of $(H / E)$, since Poisson's ratio has only a small effect. For all pure metals, $\epsilon_{\mathrm{e}}<1 \%$ and $0.9<\delta_{\mathrm{H}}<1.0$. A value of $\delta_{\mathrm{H}} \geq 0.9$ is a necessary condition for room temperature plasticity.

The value of elasticity and plasticity parameter computed from the above hardness values is shown in Fig. 3(a-b). It is clear that the elasticity parameter decreases with an increase in temperature and reaches close to zero above $1073 \mathrm{~K}$ (Fig. 3a). Consistent with this behaviour, plasticity parameter computed from Eq. (9) shows a reverse trend. Plasticity was found to increase with the increase in temperature and reaches a value of near unity at $1073 \mathrm{~K}$ (Fig. 3b). For many metals, hardness falls substantially with increasing temperature and its effect is much stronger than that of decrease of Young's modulus in the same temperature interval. At the same time, the temperature dependence of Poisson's ratio is weak, hence $\delta_{\mathrm{H}}$ increases as temperature increases. The plasticity parameter gives an indication of material's ability to deform without the formation of cracks. A value of $\delta_{\mathrm{H}}>0.9$, preferably $>0.95$, is required for room temperature plastic deformation. As can be seen from Fig. $3 \mathrm{~b}$. the value of $\delta_{\mathrm{H}}$ was 0.84 at room temperature indicating the brittle nature of the alloy at room temperature. The value of $\delta_{\mathrm{H}}$ was above 0.94 at $873 \mathrm{~K}$ and it increases with further increase in temperature, showing hot deformation is feasible at these temperatures. $\delta_{\mathrm{H}}$ is sensitive to structural and substructural state of the material and this value can be used for the investigation and control of thermomechanical treatments. 

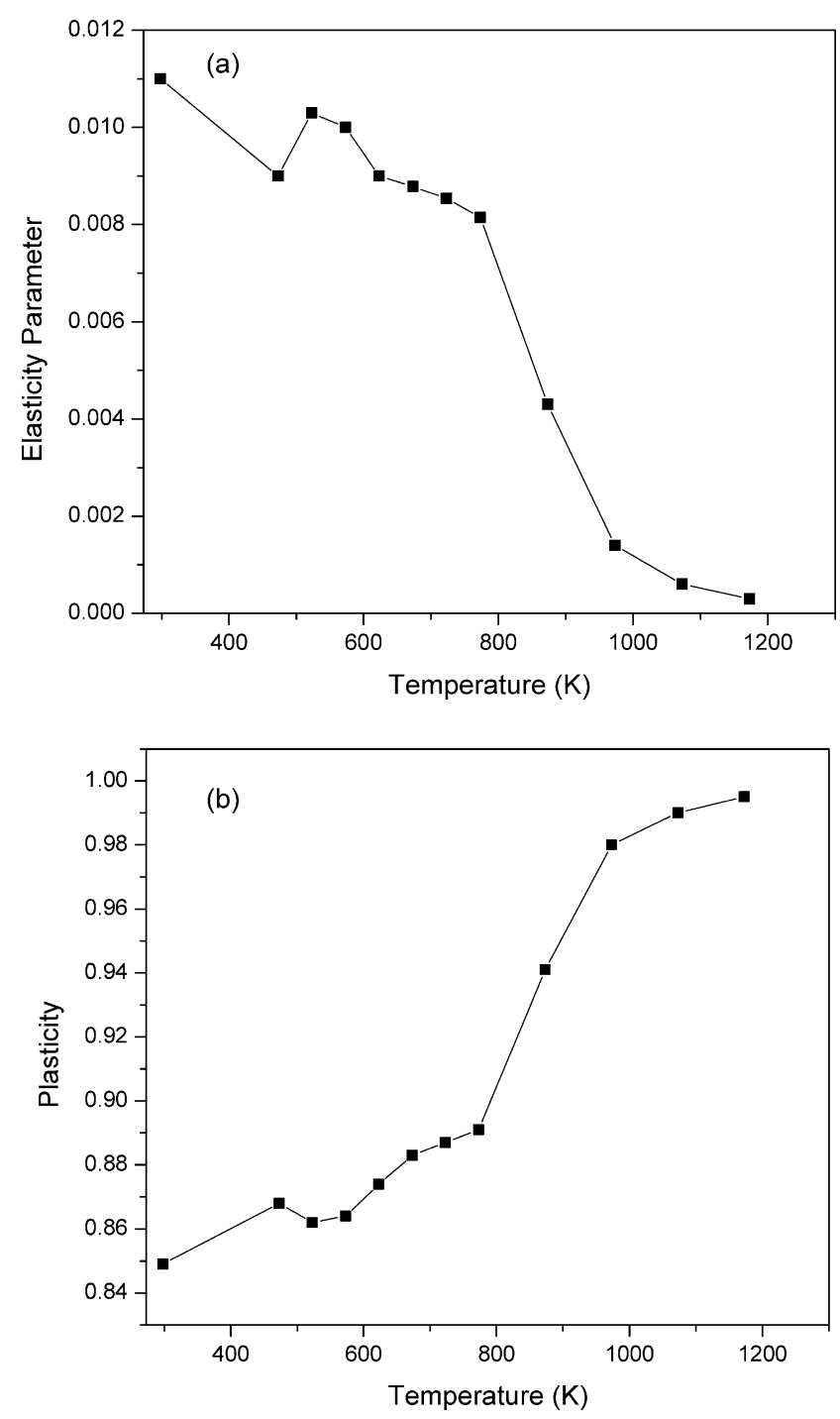

Fig. 3. (a) Variation of Elasticity parameter of iron aluminide with temperature. (b) Variation of Plasticity parameter of iron aluminide with temperature.

\subsection{Indentation creep}

In an elastic-plastic analysis of the hardness test, when an indenter is pressed into the flat surface of the solid, the indenter is encased in a non-deforming hemispherical core within which there is assumed to be a hydrostatic pressure. Outside this zone, there exists a plastic-elastic hemispherical zone surrounding the hydrostatic zone. The process of indentation is thus likened to be the plastic movement of a series of shells concentric with the hemispherical core into the bulk of the specimen [28]. In this study, we have adopted the dimensional analysis approach of Sargent and Ashby [25] to analyze the results obtained.

There are a number of possible mechanisms which may contribute to high temperature creep in intermetallics, e.g. diffusional processes, dislocation glide and climb, grain boundary sliding as well as other effects due to the ordered atomic structure (such as change in vacancy concentration, different values for activation energies for diffusion or deformation process, etc.) $[14,15,19]$. However, the high temperature deformation mechanisms of these aluminides have not been extensively studied. Only limited studies on creep strength of $\mathrm{Fe}_{3} \mathrm{Al}$ alloys have been published [11,13, 14]. Lawley et al. [13] have studied creep in Fe-Al alloys containing up to 28 at\% Al. Sauthoff et al [16-18] have reported that creep in B2 ordered structures was not fundamentally different from classically disordered alloys. Compression creep studies have shown that $\mathrm{FeAl}$ deforms by two independent deformation mechanisms, with the same activation energy in the temperature range of $1100-1400 \mathrm{~K}$ [29-32]. Both mechanisms are dependent on grain size, however, for higher stress regime $(n>5)$ strength increases with a decreasing grain size, while for lower stress-exponent $(n<5)$ the opposite is true. Under the experimental conditions when power law creep is valid, the value of the stress exponent $n$ can be used to identify the mechanisms controlling the deformation as either: diffusional creep $(n \approx 1)$, dislocation glide $(n \approx 3)$, dislocation climb ( $n \approx 4-5$ ), or particle strengthening ( $n \geq 6$ ) [16-18].

High temperature creep of single-phase materials can be characterized by stress exponent and activation energy values. Fig. 1 shows $\log -\log$ plot of hardness and dwell time at $843,873,903,933$ and $963 \mathrm{~K}$. The slope of each line is equal to the value of $(-1 / n)$ for creep. The magnitude of $n$ was found to lie in the range (4.5-5.5), as expected for high temperature power-law creep controlled by dislocation climb mechanism. As discussed by $\mathrm{Li}$ et al. [6], the dislocation density built in the elastic-plastic zone due to indentation increases under the influence of stresses at high temperature. Due to these stresses the material will flow from this elastic-plastic zone to the surface of the sample. This will lead to dislocation climb as the rate controlling mechanism. At elevated temperatures, if a gliding dislocation was held up by an obstacle, a small amount of climb might permit it to surmount the obstacle, allowing it to glide to the next set of obstacles where the process was repeated. This glide step produces almost all of the strain but the climb step controls the velocity. Dislocation climb requires diffusion of vacancies; the rate-controlling step is therefore atomic diffusion. Diffusional processes are more difficult in ordered lattices because of the tighter inter-atomic binding between the dissimilar atoms and the longer distance between equivalent lattice sites. Thus, the activation energies for the formation and migration of vacancy increase with order, resulting in higher activation energies for diffusion and for creep, and therefore lower creep rates [14]. The stress exponent was found to decrease with increasing temperature, from 5.52 to 4.53 as the temperature increased from 843 to $963 \mathrm{~K}$. Indentation tests are carried out at high values of stress. At such stresses many excess vacancies can be generated by dislocation intersection process. 


\subsubsection{Thermal activation parameters}

Two important thermal activation parameters often used for the identification of the operating creep mechanism are the activation energy and the activation area The activation area can be defined as:

$A^{*}=\left(\frac{k T}{b}\right)\left(\frac{\delta \ln \dot{\varepsilon}}{\delta \sigma_{s}}\right)$

where $A^{*}$ is the activation area and $\dot{\varepsilon}$ is the creep rate (in general the deformation rate), $k$ is the Boltzmann constant and $b$ is the Burgers vector. In the indentation creep testing, it is not possible to directly evaluate the deformation partial $\delta \ln \dot{\varepsilon} / \delta \sigma_{s}$. However, if a conventional creep curve could be derived from the hardness time plots (hardness versus time curves), the deformation partial in Eq. (10) can be estimated. The models developed by Mulhearn et al. [33] assumes that the indentation produces an average representative strain given by:

$\varepsilon=A^{\prime}(\mathrm{d} / \mathrm{D})^{b^{\prime}}$

where $d$ and $D$ are the diameters of the indentation and the indentor, respectively, and $A^{\prime}$ and $b^{\prime}$ are constants, the value of $b^{\prime}$ is suggested to be 1 .

A similar model proposed by Atkins [34] suggests that $b^{\prime}$ should be 1.5. If $D$ is kept constant, the above Eq. (11) would show that $\varepsilon \propto d$ and since $H \propto d^{-2}$, substituting $H$ in place of $d$ for constant load, one can arrive at

$\varepsilon \propto 1 / \sqrt{H}$

Similarly, for Atkins model one can arrive at

$\varepsilon \propto 1 /(H)^{1.5}$

The conventional creep curve can be derived by plotting $(1 / H)^{1.5}$ as a function of time. However, in the literature it has been shown that converting the hardness time relationship into conventional creep curves and then estimating the activation energy using Atkin's model were in better agreement with the values of activation energy calculated from the conventional creep data. Typical conventional creep curves derived from the Atkin's model are shown in Fig. 4. Here the strain is equated to $(1 / H)^{1.5}$ and therefore is in arbitrary units. In this curve, a near steady state seems to have been attained after $100 \mathrm{~s}$. For small times the creep strain is almost primary in nature. Indentation tests are high stress test. The stress generated during the indentation process is estimated to be greater than $E / 1000$ where $E$ is the Young's modulus. Since the stresses are higher in the indentation tests, the onset of secondary creep is expected to be faster. Kutty et al. [35] have transformed the hardness time plots into conventional creep for various alloys like stainless steel AISI 316 and zircaloy 2 . From the resultant creep curves, the activation energy for creep computed was found to be comparable with those in the reported in the literature.

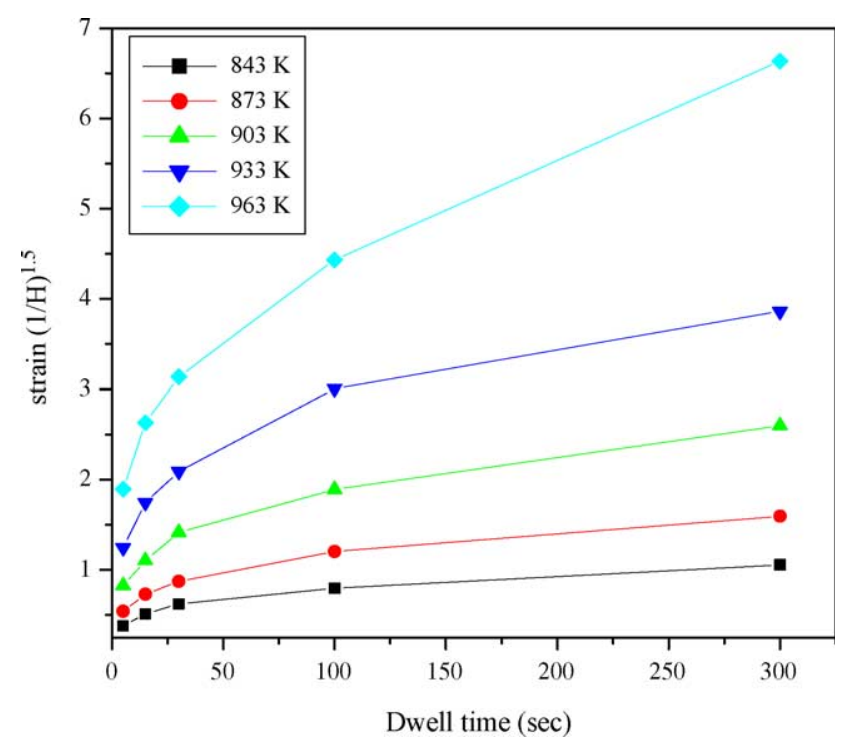

Fig. 4. Conventional creep curve for iron aluminide derived from hardness values.

The activation area is computed in the following manner: Two creep strain values are selected along a creep curve (constant temperature) and the corresponding creep rates are computed, from the slope of the creep curve. The hardness values corresponding to the two selected strain values are known and hence the stress values can be computed (from the applied load and the projected area of indentation). The quantity $\Delta \ln \dot{\varepsilon} / \Delta \sigma_{s}$ is then calculated and substituted in Eq. (10) to yield the activation area. The computed value of activation area was found to be $1.74 b^{2}$ which is representative and have to be considered as only order of magnitude estimates.

In a similar way the activation energy for creep can also be computed from the derived creep curves. The relevant expression used for this computation is:

$Q=R\left[\ln \left(t_{1} / t_{2}\right)\right] /\left(1 / T_{1}-1 / T_{2}\right)$

where $t_{1}$ and $t_{2}$ are the time to reach a given strain (i.e. a given hardness) value at two temperatures $T_{1}$ and $T_{2}$. A constant hardness means a constant area of indentation and since load was kept constant, the situation corresponds to a constant stress, thus validating the procedure employed for calculating $Q$ (Fig. 2). These experimental results showed that the activation energy for high temperature creep lies in the range of 339-341 kJ/mol. McKamey [14] has reported creep activation energy of $334-355 \mathrm{~kJ} / \mathrm{mol}$ in the same temperature range, which is in excellent agreement with the experimental results of the present study. An activation energy value of $355 \mathrm{~kJ} / \mathrm{mol}$ has also been reported in the temperature range of 843-963 K [13], which also compares favourably with the present results. Chen et al. [20] reported that, at $873 \mathrm{~K}, \mathrm{Fe}_{3} \mathrm{Al}$ alloys exhibit dislocation creep as rate controlling creep mechanism which further supports the results of this paper. Similar values of activation energy of plastic flow were obtained in 
Ref. [36] for FeAl based alloy. However, a recent review by Jordon et al. [37] showed that the activation energy of iron aluminides lies in the range of $250-300 \mathrm{~kJ} / \mathrm{mol}$. Malek et al. [38] have reported an activation energy of $280 \mathrm{~kJ} / \mathrm{mol}$ for high temperature deformation of $\mathrm{Fe}_{3} \mathrm{Al}$ based alloys. They have also reported stress exponent values in the range of 4-5 which are in good agreement with the present study. Activation energy obtained in the present study is slightly higher than those reported in Ref. [37]. As suggested by Sherby and Burke [39] the effect of temperature on elastic modulus should be taken into account when calculating the activation energy for creep. The present study did not make the above corrections for the modulus while calculating activation energy. This could be one of the reasons why the calculated value of activation energy for creep was slightly higher than that for self-diffusion. Since self-diffusion depends on vacancy interchange with atoms, the activation energy is the sum of the formation and migration of vacancies. Agreement between the values of the activation energies of creep and self-diffusion of pure iron suggests that dislocation climb is the rate controlling mechanism.

Several mechanisms have been proposed in the literature to account for the creep rate observed at high temperatures. Mechanisms based on diffusional flow such as HerringNabarro creep and Coble creep can be straight away discounted since these models require $n$ to be unity or nearly so. The observed values of $n$ are much higher and lies in the range of 4.5-5.5. Two mechanisms have been mainly referred to in the literature which predict $n$ values in the experimental range of 4-7 [40,41]. These are (i) the model of climb of edge dislocation (ii) the model of jogged screw dislocation motion. While the expected activation energy for creep is the same for the two mechanisms (namely activation energy for self diffusion), they are distinguishable on the basis of the activation area. The climb model requires $A^{*}$ to be about $b^{2}$ while that for non-conservative motion of jogs is a few hundred $b^{2}$. The experimental activation area was close to $1.74 b^{2}$, which shows that dislocation climb was the rate controlling mechanism. Based on the values of $n, A^{*}$ and $Q$ obtained in the present study it is concluded that dislocation climb was the high temperature creep mechanism.

\section{Conclusions}

The indentation creep behaviour in the temperature range of $843963 \mathrm{~K}$ of a $\mathrm{Fe}-28 \mathrm{Al}-3 \mathrm{Cr}$ was evaluated in this study. The results showed that the stress exponent varied between 4.5 and 5.5 with temperature. These values of stress exponent lie in the range expected for high temperature power-law creep controlled by dislocation climb mechanism. The value of activation energy for creep was found to be comparable to the activation energy for the self-diffusion of pure iron, also indicating that dislocation climb was the rate controlling mechanism. Further, the activation area calculated was also showed consistent with dislocation creep as the rate controlling mechanism. Thus, it can concluded that the $\mathrm{Fe}-28 \mathrm{Al}-3 \mathrm{Cr}$ undergoes creep by dislocation climb mechanism.

\section{Acknowledgements}

The authors would like to thank Dr P.K. De, Head, Materials Science Division and Dr S. Banerjee, Director, Materials Group, for their encouragement. The authors would also like to thank Mr K. Ravi, Radiometallurgy Division for his help.

\section{References}

[1] Westbrook JH. Trans Am Soc Met 1953;45:221.

[2] Atkins AG. Met Sci 1982;16:127.

[3] Underwood EE. Mater Meth 1957;45:127.

[4] Geach GA. Int Met Rev 1974;19:255.

[5] Li WB, Warren R. Acta Metall Mater 1993;41:3065.

[6] Li WB, Henshall JL, Hooper RM, Easterling KE. Acta Metall Mater 1991;39:3099.

[7] Chiang D, Li JCM. J Metal Res 1994;9:903.

[8] Okada A, Yamamolo Y, Yoda R. J Iron Steel Inst Japan 1987;73: 1186.

[9] McKamey CG, Liu CT. Scripta Metall Mater 1990;24:2119.

[10] McKamey CG, Horton JA, Liu CT. High temp ordered intermetallic alloys II. In: Stoloff NS, Koch CC, Liu CT, Izumi O, editors. Materials Research Society Proceedings, vol. 81.; 1987. p. 321.

[11] McKamey CG, Devan JH, Tortorelli PF, Sikka VK. J Mater Res 1991; 6:1779.

[12] Sikka VK. Ductility enhancement of iron aluminide alloy. SAMPE Q 1991;7:2.

[13] Lawley A, Coll JA, Cahn RW. TMS AMIE 1960;218:166.

[14] McKamey CG, Maziasz PJ, Jones JW. J Mater Res 1992;7:2089.

[15] Garofalo CF. Fundamentals of creep and creep rupture in metals. New York: The Macmillan Co; 1965.

[16] Rudy M, Sauthoff G. Mater Sci Engng 1986;81:525.

[17] Rudy M, Sauthoff G. In: Koch CC, Liu CT, Stoloff NS, editors. High temperature ordered intermetallic alloys. Materials Research Society Symposium Proceedings, vol. 39.; 1985. p. 327. Pittsburgh, PA.

[18] Jung I, Rudy M, Sauthoff G. In: Koch CC, Liu CT, Stoloff NS, Izumi O, editors. High temperature ordered intermetallic alloy II. Materials Research Society Symposium Proceedings, vol. 81.; 1987. p. 263. Pittsburgh, PA.

[19] Sherby OD, Burke PM. Prog Mater Sci 1968;13:325.

[20] Chen G, Huang Y, Yang W, Sun Z. In: Schneibel JH, Crimp MA, editors. Processing, properties and applications of iron aluminides. The minerals, metals and materials society; 1994. p. 131.

[21] Dakshinamurthy VK, Baligidad RG. Mater Sci Engng 2002;A328: 58-61.

[22] Deevi SC. Swindeman. Mater Sci Engng, A 1998;258:203-10.

[23] Sundar RS, Sastry DH. Intermetallics 2000;8:1061-5.

[24] Mckamey CG, Maziasz PJ. Intermetallics 1998;6:303-14.

[25] Sargent PM, Ashby MF. Mater Sci Technol 1992;8:594.

[26] Sharma G, Ramanujan RV, Kutty TRG, Tiwari GP. Mater Sci Engng 2000;A278:106-12.

[27] Milman YuV, Galanov BA, Chugunova SI. Acta Metall Mater 1993; 41:2523.

[28] Johnson KL. J Mech Phys Solids 1970;18:115. 
[29] Whittenberger JD. Mater Sci Engng 1983;57:77.

[30] Whittenberger JD. Mater Sci Engng 1986;77:103.

[31] Vedula K, Stephens JR. Mater Res Soc Symp Proc 1987;81:381.

[32] Titran RH, Vedula K, Anderson G. Mater Res Soc Symp Proc 1985; 39:319.

[33] Mulhearn TO, Tabor D. J Inst Met 1960-1961;89:7.

[34] Atkins AG. In: Westbrook JH, Conard H, editors. The science of hardness testing and its research applications. Metal Park, OH: ASM; 1971. p. 223.
[35] Kutty TRG, Ganguly C, Sastry DH. Scripta Mater 1996;34(12):1833.

[36] Krupa M. Intermetallics 2004;12:295-302.

[37] Jordon JL, Deevi SC. Intermetallics 2003;11:507-28.

[38] Malek P, Kretochvil P, Pesicka J, Hanus P, Sediva I. Intermetallics 2002;10:985-92.

[39] Sherby OD, Burke PM. Mechanical behaviour of crystalline solids at elevated temperatures. New York: Pergamon Press; 1968.

[40] Weertman J. J Appl Phys 1955;26:1213.

[41] Weertman J. J Appl Phys 1957;28:362. 